\title{
A educação física na educação de jovens e adultos: a concepção dos estudantes de um município do interior da bahia
}

\author{
Tatiana Silva da Conceição ${ }^{1}$ \\ Claudio Roberto de Jesus Pereira ${ }^{2}$ \\ Rafaela Gomes dos Santos ${ }^{3}$
}

\begin{abstract}
Resumo: A Educação de Jovens e Adultos (EJA) é uma modalidade da Educação Básica, destinada às pessoas que não tiveram acesso ou continuidade dos estudos na idade própria. Assim, investigar a Educação Física em tal âmbito é de grande relevância para compreendermos a importância de incluí-la na EJA, a fim de contribuir para o desenvolvimento desses sujeitos. O objetivo do estudo foi analisar a concepção de Educação Física por alunos do segundo segmento da EJA de uma escola pública em Teixeira de Freitas - Bahia. Trata-se de uma pesquisa qualitativa, de cunho descritivo e utilizou-se como técnica de interpretação dos dados a análise de conteúdo. Após a análise, foram emergidas as seguintes categorias: "Compreensão da educação física"; "Conhecimento acerca da educação física"; "Vivência com o professor graduado"; "Obrigatoriedade da disciplina na EJA". Os resultados mostraram que na primeira categoria, $28 \%$ dos estudantes consideraram a educação física benéfica para a saúde, $21 \%$ relataram a importância no desenvolvimento da relação corpo/mente e $20 \%$ a compreendem somente como esportes; na segunda categoria, 37\% demonstraram ter conhecimentos sobre esportes, em específico, o futebol, que nos leva a reflexão desse esporte tão conceituado no país e em nosso cotidiano; na terceira categoria, $82 \%$ dos estudantes, já tiveram contato com a disciplina de educação física; e na última categoria, $76 \%$ gostariam de tê-la como obrigatória na EJA, tanto para exercitar o físico, quanto o cognitivo, todavia, $3 \%$ disseram que não gostaria por questões de gênero e pela desvalorização da Educação Física, o que nos leva a discutir e pensar em estratégias, visando a melhoria das aulas de Educação Física no âmbito escolar. Diante dos resultados emergentes, torna-se necessário elucidar a importância de gestores e professores terem um olhar mais aprofundado para os alunos desse contexto escolar e junto com o poder público tomar medidas, sejam em pequenas ações no cotidiano, ou por políticas públicas, a fim de oportunizar melhores condições de aprendizagem na EJA.
\end{abstract}

Palavras - chave: Educação Física. Educação de Jovens e Adultos. Estudantes.

\section{The understanding of physical education by students of the second segment of eja from a public school in teixeira de freitas - ba}

\begin{abstract}
The Youth and Adults Education (EJA) is a modality of basic education for people who did not have access or could not continue their studies in the proper age. Therefore, investigating Physical Education in this area is important to understand the relevance of including it in EJA, in order to contribute to the development of these individuals. The objective of this study was to analyze the

\footnotetext{
${ }^{1}$ Graduada e licenciada em Educação Física pela Universidade do Estado da Bahia - UNEB. Teixeira de Freitas - BA. E-mail: tatianasilva.ts@ hotmail.com

${ }^{2}$ Especialista em Fisiologia do Exercício. Professor do colégio Estadual Democrático Ruy Barbosa. Teixeira de Freitas - BA. E-mail: claudio.mundial@ gmail.com

${ }^{3}$ Mestra em Educação Física. Professora da Universidade do Estado da Bahia - UNEB. Campus X. Teixeira de Freitas. E-mail: rafagomes.edf@gmail.com
} 


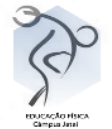

understanding of Physical Education by students of the second segment of EJA from a public school in Teixeira de Freitas-Bahia. This is a qualitative research, with a descriptive nature and as a technique for interpreting the data it was used the content analysis. After this analysis, it was raised the following categories: "Comprehension of physical education"; "Knowledge about physical education";

"Experience with a licensed teacher", "Obligatoriness of physical education in EJA." The results have shown that in the first category, $28 \%$ of the students considered that physical education is beneficial for health, $21 \%$ reported the importance in the relation of body/mind and $20 \%$ understood it only as sports; in the second category, $37 \%$ showed knowledge about sports, specifically soccer, which leads us to reflect on this highly regarded sport in the country and in our daily lives; in the third category $82 \%$ of the students had contact with the subject of physical education; and in the last category $76 \%$ would like to have it as mandatory in EJA for both physical and cognitive exercise, however, 3\% said they would not like it for gender issues and for the devaluation of physical education at school. Given the emerging results, it is necessary to elucidate the importance of managers and teachers having a deeper look at the students in this school context and together with the public authorities, take measures, whether in small daily actions or by public policies in order to provide better learning conditions in EJA.

Keywords: Youth and Adult Education/EJA. Students. Physical Education.

\section{INTRODUÇÃO}

A Educação de Jovens e Adultos (EJA) é uma modalidade da Educação Básica, destinada, de acordo com o artigo 37 da Lei de Diretrizes e Bases da Educação Nacional (LDB) n 9394 de 1996, às pessoas que não tiveram acesso ou continuidade de estudos na idade própria (BRASIL, 2019).

A EJA é norteada por princípios éticos que perpassam desde fundamentos morais, como solidariedade, responsabilidade, autonomia, até os políticos e estéticos, como direitos e deveres dos cidadãos e apreciação dos diversos tipos de manifestações artísticas e culturais (BRASIL, 2013).

Comumente, os estudantes que frequentam essa modalidade de ensino vivem em uma realidade de desigualdade e exclusão social, que é influenciada por fatores internos, como a má qualidade educacional do ensino do sistema público, podendo ser de cunho administrativo, infraestrutural ou pedagógico, e por fatores externos, como as diferenças econômicas e regionais do meio em que vivem, que muitas vezes induz ao conhecimento limitado para esses jovens e adultos (HADDAD; SIQUEIRA, 2015). 
No que se refere ao componente curricular Educação Física, de acordo com a LDB, é um dos componentes obrigatórios da educação básica e, mediante a Lei no 10.793 de 1 de dezembro de 2003, fica facultativa sua prática ao aluno que tenha jornada de trabalho igual ou superior a seis horas, maior de trinta anos de idade, que presta serviço militar ou similar e que tenha prole (BRASIL, 2003).

Neste contexto, a legislação não estimula a Educação Física como disciplina legitimada em todos os níveis da Educação Básica, posto que faculta a sua prática para alunos de alguns segmentos.

As aulas de Educação Física podem viabilizar a compreensão do ser humano e suas totalidades, a diversidade corporal, bem como o corpo como sujeito e não como objeto. Essa concepção de Educação Física, trabalha buscando a formação da autonomia e da criticidade, afinal, o corpo não existe isoladamente, a realidade sócio-histórica e cultural do indivíduo contribui para a formação do sujeito como todo (CARVALHO, 2013).

Sendo assim, analisar a concepção dos estudantes da EJA acerca da Educação Física, se faz importante para refletirmos sobre a realidade atual desse componente no âmbito escolar, além de despertar a atenção da sociedade e órgãos públicos para as necessidades de melhorias no ensino-aprendizagem e desenvolvimento desses educandos.

Portanto, este estudo tem como objetivo analisar a concepção de educação física por alunos do segundo segmento da EJA de uma escola pública em Teixeira de Freitas Bahia.

\section{PROCEDIMENTOS METODOLÓGICOS}

O presente estudo tem caráter descritivo com abordagem qualitativa. Segundo Gomes (2008), a pesquisa qualitativa visa analisar um conjunto de opiniões e sua representação social sobre o tema a ser pesquisado, no qual, deve-se considerar os aspectos heterogêneos e individuais que os diferenciam mesmo estando em um contexto social igual.

As aulas do ensino fundamental na EJA são divididas em dois segmentos, sendo eles: o primeiro segmento de $1^{\circ}$ ao $5^{\circ}$ ano e o segundo segmento de $6^{\circ}$ ao $9^{\circ}$ ano. A população 


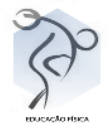

deste estudo é composta por 128 estudantes matriculados no segundo segmento da EJA em uma escola pública de Teixeira de Freitas - Bahia.

Para coleta de dados, foi aplicado um questionário composto por quatro questões abertas, relacionadas a concepção da Educação Física na EJA. Por seguinte, os alunos respondiam as questões conforme seu entendimento sobre o assunto. A análise dos dados, foi feita por meio de análise de conteúdo (GOMES, 2008). Focalizada nos principais pontos que emergiram a partir das respostas de cada estudante.

Assim, foi verificada as similaridades e diferenças dessas temáticas. A partir da análise dos dados, foram identificadas quatro categorias, a saber: "Compreensão de educação

Física"; "Conhecimento acerca da educação física"; "Vivência da educação física com o professor da área"; e "Obrigatoriedade da educação física na EJA".

\section{RESULTADOS E DISCUSSÃO}

A primeira categoria, "Compreensão de educação física", demonstrou que $28 \%$ dos estudantes tinha a compreensão de que as aulas de Educação Física eram benéficas para a saúde. Por outro lado, 24\% viam a Educação Física na perspectiva da ludicidade e divertimento, afirmando que as aulas eram legais. Outra parcela (21\%) relatou a compreensão como forma de conscientização do corpo e, ainda, citaram a articulação entre "corpo e mente". No que tange à compreensão das aulas como brincadeiras e esportes, $20 \%$ relataram perceber somente através dessa perspectiva. E, por fim, 3\% disseram compreender as aulas de forma ruim para a socialização.

Com base nessa primeira categoria, percebe-se que a maioria dos alunos compreendem a Educação Física como algo benéfico para a saúde e sua importante função na promoção da consciência corporal, física e mental. Esses aspectos podemos observar na seguinte fala:

"Muito bom, acho que todos nós deveríamos fazer, pois nos ajuda em nosso corpo, a nossa saúde e nosso metabolismo e, principalmente, faz bem ao nosso coração" $\left(8^{\circ} \mathrm{A}\right)$. 
Segundo Santos (2018), motivar os alunos a praticarem atividade física regular para a saúde e bem-estar, envolve aspectos multifatoriais, como variáveis psicológicas, sociais, ambientais e genéticas. Assim, a prática de atividade física nas aulas de educação física, terá relação direta com a qualidade de vida dos alunos, no qual, Nahas (2017) a conceitua como um conjunto de parâmetros individuais como a hereditariedade e estilo de vida e aspectos socioculturais e ambientais, onde a escola atua diretamente na formação, tendo influência em seu convívio diário. Para tanto, é necessário que a Educação Física escolar esteja voltada para contribuição da saúde, favorecendo a diminuição da inatividade física e conscientização do estilo de vida ativo (SANTOS, 2018).

A segunda categoria, "Conhecimento acerca da educação física", foi identificado que $37 \%$ dos estudantes já tinham praticado algum tipo de esporte ou outros tipos de atividade física, como ginásticas, caminhada, musculação e outros. Vale destacar, que ainda nessa categoria, $33 \%$ dos alunos relataram que o conhecimento sobre educação física está diretamente ligado a saúde e $6 \%$ compreendiam como uma disciplina teórico-prático. Contudo, o estudo mostrou que $22 \%$ dos entrevistados não tinham conhecimento sobre essa disciplina.

Segundo Freire e Oliveira (2004), a Educação Física tem sido vista como uma disciplina focada somente no "saber fazer". Sabe-se que a prática é muito importante para iniciação do ensino da disciplina, entretanto, trabalhar somente a prática não alcançará o resultado desejado para o desenvolvimento dos alunos, para isso, é necessário que juntamente com o "saber fazer" se ensine o "saber sobre" e "saber ser", sendo as dimensões procedimental, conceitual e atitudinal, respectivamente, pois a partir daí, o aluno compreenderá o porquê de executar determinado movimento, quais seus benefícios e os valores atribuídos por eles.

Ao se trabalhar as três dimensões do conhecimento no processo de ensino e aprendizagem, são resgatados valores como socialização, cooperação, criatividade, valorização do trabalho em equipe ou respeito as normas e convivência (DARIDO, 2012; FREIRE; OLIVEIRA, 2014).

Tabela 1- Concepção de Educação Física em alunos do segundo segmento da EJA de uma escola pública em Teixeira de Freitas 


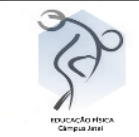

\begin{tabular}{|c|c|c|}
\hline QUESTÕES & RESPOSTAS & $\%$ \\
\hline \multirow{8}{*}{ O que você acha da Educação Física? } & É muito bom para a saúde & 28 \\
\hline & É legal & 24 \\
\hline & $\begin{array}{l}\text { É bom porque conscientiza o cuidado com o corpo } \\
\text { e ajuda em seu funcionamento e articula corpo e } \\
\text { mente }\end{array}$ & 21 \\
\hline & É bom porque tem brincadeiras e esportes & 20 \\
\hline & É ruim & 3 \\
\hline & É bom para socializar & 1,56 \\
\hline & Melhor matéria do mundo & 0.78 \\
\hline & $\begin{array}{l}\text { Jogar futebol, vôlei, basquete, handebol, peteca, } \\
\text { queimada, fazer academia, caminhada, bicicleta }\end{array}$ & 37,5 \\
\hline \multirow[t]{3}{*}{ O que você sabe sobre educação física? } & Ajuda na saúde & 33 \\
\hline & Não sei nada & 22 \\
\hline & Que tem teórico e prático e ajuda no físico e mental & 6 \\
\hline \multirow{4}{*}{$\begin{array}{l}\text { Você já fez aula de educação física } \\
\text { com o professor da área? }\end{array}$} & Sim & 82 \\
\hline & Não & 18 \\
\hline & $\begin{array}{l}\text { Sim, para ter um intervalo para praticar esporte, } \\
\text { exercitar, melhorar a saúde, distrair, entusiasmar }\end{array}$ & 50 \\
\hline & $\begin{array}{l}\text { Sim, porque ajuda no desenvolvimento do corpo e } \\
\text { na educação }\end{array}$ & 26 \\
\hline \multirow{4}{*}{$\begin{array}{c}\text { Você acha que as aulas de educação } \\
\text { física deveriam ser obrigatórias na } \\
\text { EJA? Porquê? }\end{array}$} & Não, porque não gosto & 4 \\
\hline & $\begin{array}{l}\text { Não, porque só os meninos participam, jogando } \\
\text { futebol }\end{array}$ & 3 \\
\hline & $\begin{array}{l}\text { Não, porque nunca tive contato com educação } \\
\text { física }\end{array}$ & 3 \\
\hline & Não, porque ia atrapalhar os estudos & 2 \\
\hline
\end{tabular}

Fonte: Dados do pesquisador

Nesse estudo, vimos que a maioria dos alunos da EJA (37\%) abordam a Educação Física somente como esporte, em específico o futebol, isso impossibilita a comunidade em enxergá-la como uma disciplina ampla e rica de conhecimento dentro do contexto escolar (SANTOS, 2018). Desse modo, é importante destacar que não basta entender como se joga o futebol, é necessário ver como o esporte acontece dentro de sua comunidade, em sua realidade e identificar seu papel sociocultural no meio em que vive. Tendo como base essas informações, o aluno poderá se constituir como pessoa autônoma, capacitada para intervir e transformar o meio onde reside (SOARES et al., 2012). 
A terceira categoria, "Vivência da educação física com o professor da área", a maioria dos alunos (82\%) disse já ter feito aulas da disciplina com o professor capacitado/formado. A partir disto, percebe-se que os estudantes já tiveram contato com a Educação Física em algum momento de suas vidas.

Cumpre-se explicitar que o professor detém grande responsabilidade para a formação integral do aluno (FREIRE; OLIVEIRA, 2014), ele é o elemento de ligação entre a vida externa e interna, é através das relações em sala de aula que vivências e descobrimentos são oportunizados (GALVÃO, 2002).

As aulas de Educação Física proporcionam momentos de forma de expressão, socialização interpessoal, conceitos e valores que podem ser trabalhados com um caráter transformador. Ser professor é preocupar-se com a intervenção adequada de acordo com o contexto social dos estudantes; é extrapolar os limites e dificuldades encontradas, proporcionando mudanças no cotidiano de cada um através do conhecimento (GALVÃO, 2002) e isso deverá ser garantindo também na EJA (GONÇALVES, 2019).

$\mathrm{Na}$ última categoria, intitulada de "Obrigatoriedade da educação física na EJA" foi possível perceber que $50 \%$ dos alunos disseram que gostariam que o componente curricular Educação Física fosse obrigatório. Segundo os estudantes entrevistados seria bom ter um intervalo para praticar esportes, exercitar, melhorar a saúde, além da distração e motivação.

Ressalta-se que os alunos da EJA souberam identificar os benefícios da prática de atividade física e sua importância na escola, como oportunidade para adquirirem conhecimento e vivenciarem várias atividades proporcionadas pela disciplina, ainda, veem como possibilidade de diminuir o comportamento sedentário, como podemos observar nas seguintes falas:

\footnotetext{
"Sim, porque ajuda na interatividade de todos os alunos, inclusive com o professor e também ajuda a manter uma boa qualidade de vida para os alunos, para eles ficarem mais felizes" $\left(9^{\circ} \mathrm{B}\right)$.

"Sim, é importante porque existe muitos alunos sedentários que não praticam exercício físico tanto na EJA ou em outros ensinos, mas é muito importante mesmo
} 


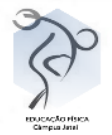

ter aula de educação física nas escolas para influenciar os alunos a praticar exercícios" ( $\left.8^{\circ} \mathrm{B}\right)$.

Pich e Fontoura (2013) questionam as mudanças ocorridas na LDB ao abordar a Educação Física, anteriormente, com a Lei n 9394/96 houve uma evolução no sentido de se tornar um componente curricular integrado à proposta pedagógica da escola e não mais vista como uma atividade no currículo escolar. Entretanto, ao colocar a Educação Física como obrigatória na Educação Básica, conquanto facultativa aos cursos noturnos, apresenta uma contradição, posto que acaba por inferiorizar a Educação Física, prevalecendo outras disciplinas na EJA e a excluindo desse espaço educacional.

Contudo, a prevalência de inserção de jovens na EJA se faz cada vez mais presente, isso tem ocorrido devido ao aumento de jovens no mercado de trabalho, principalmente em camadas sociais de baixa renda. Outro fator é quando o estudante em turno regular é visto como "aluno-problema", sendo muitas vezes direcionado para as aulas no período noturno (CARVALHO, 2009).

Além disso, EJA se torna atrativa devido a possibilidade de realizar exames supletivos, no ensino fundamental, a partir de 15 anos, e, ensino médio, a partir de 18 anos, sendo um fator para o crescimento de jovens na EJA (BRASIL, 2018). Segundo Gomes e Garcia (2014) a idade dos alunos da EJA atualmente é, predominantemente, de 18 a 25 anos de idade.

Para isso, a LDB atualizada transfere o caráter facultativo para os alunos e não mais para a escola, como antes. Assim, cabe ao alunado da EJA se adequar aos critérios estabelecidos na LDB, para fazer jus ao direito de ter Educação Física na EJA, todavia, destaca-se que essa inserção não se efetiva devido a vários fatores, entre eles podemos destacar a facultatividade, a falta de espaços favoráveis e a hierarquia da disciplina (PEREIRA; MAZZOTI, 2008).

Um estudo realizado por Carvalho (2009) com 104 alunos da EJA foi identificado que o perfil dos estudantes era de maioria solteiros e de baixa renda. Dentre os motivos de estudarem na EJA, 80\% destacaram o trabalho e mudanças. Porém, os autores viram que $25 \%$ dos jovens não trabalhavam. Esse fato despertou atenção, pois o número de jovens que não trabalham está crescendo cada vez mais na EJA. Um dos argumentos para esse 


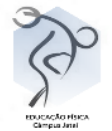

fato é que, ao continuar com os estudos, permanecem a morar com os pais, por não conseguirem se autossustentar.

Tendo em vista a constância desse cenário, há necessidade de refletir sobre a adequação da LDB ao perfil dos estudantes da EJA. Então, sobre tal perspectiva, a alguns estudantes comentaram:

"Sim, porque de manhã e de tarde tem, nada mais justo ter de noite também" $\left(8^{\circ} \mathrm{A}\right)$.

\footnotetext{
"Com certeza, porque educação física também é uma matéria, e assim como as outras, também temos o direito de ter conhecimento dos esportes" $\left(8^{\circ} \mathrm{B}\right)$.

"Sim, porque é um esporte que ajuda no desenvolvimento dos alunos, o desenvolvimento do corpo e ajuda também na educação" $\left(6^{\circ} \mathrm{A}\right)$.

"Sim, porque nos ajudaria em vários aspectos" $\left(9^{\circ} \mathrm{B}\right)$.
}

Nos trechos supracitados, fica perceptível o desejo dos alunos de ter a Educação Física como disciplina obrigatória na EJA e seu questionamento acerca da obrigatoriedade em outros turnos e não no curso noturno. Além disso, muitos alunos (26\%) destacaram sua importância devido a benefícios no desenvolvimento físico e intelectual.

De fato, a Educação Física é fundamental para o desenvolvimento humano, contribui para estimulação dos sentidos (tato, audição, visão, gustação e olfato), melhora a saúde e aptidão física, e muito além disso, desenvolve o aspecto da biopsicologização, que não se baseia apenas em um ser psicológico ou biopsicológico, se baseia em salientar a natureza sócio histórica do psiquismo humano, a natureza cultural, visto que somos carreados de experiências vividas no contexto sociocultural (SOARES, 1996).

Nesse bojo, a Educação Física se propõe a estudar o movimento humano, os valores éticos-políticos do corpo e sua amplitude, bem como desenvolver a compreensão dos alunos acerca do significado de determinado movimento e seu momento histórico. Ademais, ao desenvolver a criticidade, o estudante consegue se posicionar perante aos cultos ao corpo belo e virtuoso proposto pela mídia e sociedade capitalista (SOARES, 1988).

Ainda, na mesma categoria, 3\% dos estudantes responderam que "não" deveria ser obrigatório, possivelmente devido a questões relacionadas ao gênero, no qual, só os meninos normalmente participam e jogam futebol e as meninas só observam. Essa questão fica evidente na fala a seguir: 
"Não, porque nem todos jogam, os outros que jogam, uns gostam de futebol, outros não gostam. Por isso, não deve ser obrigatório" ( $\left.7^{\circ} \mathrm{B}\right)$.

É importante salientar que as questões de gênero estão vinculadas diariamente em sala de aula, especificamente, na Educação Física, visto que a cultura dos meninos serem considerados mais habilidosos na prática e os esportes são reservados somente ao sexo masculino (DEVIDE, et al 2011; JESUS; DEVIDE, 2006).

É importante considerar os aspectos impostos pela sociedade, que delimitam essa separação entre sexo nas aulas de Educação Física. Argumentando para isso, se baseiam em fatores culturais, onde a menina normalmente é criada de forma restrita e os meninos mais livres para brincarem, outras reclamações como a violência dos meninos sobre as meninas durante o jogo, o receio delas de praticarem a atividade devido os meninos apresentarem mais habilidade e estrutura física e acharem que não haverá evolução pelo impasse entre os sexos (JESUS; DEVIDE, 2006; DORNELLES; FRAGA, 2009).

Para modificar essa realidade, o professor deve desmitificar preconceitos de aulas mistas, igualar as oportunidades durante as aulas, além disso, o professor pode optar por propostas coeducativas, buscando contribuir para a socialização, cooperação, respeito as diferenças, participação efetiva dos alunos, entre outros valores, afim de proporcionar igualdade de oportunidades (LOUZADA; VOTRE; DEVIDE, 2007).

É nesse contexto que, segundo Pereira e Santos (2019), é necessário oportunizar aos adolescentes nas aulas de Educação Física, debates sobre gênero, de modo que suas escolhas sejam mais conscientes em suas vidas, em vez de apenas aceitarem como se fossem determinados por uma ordem natural das coisas.

Ademais, outros 3\% também disse que "não", por nunca ter tido contato com a Educação Física e $2 \%$ enxergavam a disciplina como um empecilho para os estudos. Como descrito na fala seguinte:

"Não, porque ia atrapalhar os estudos" $\left(7^{\circ} \mathrm{A}\right)$.

Os estudantes, ao final do Ensino Médio, são avaliados pelo Exame Nacional de Ensino Médio (ENEM) que tem como objetivo precípuo avaliar o desempenho escolar e 


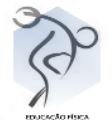

acadêmico ao fim dessa etapa. Inicialmente, o ENEM era proposto às pessoas que possuem 18 anos ou mais como possibilidade de inserção no ensino superior (BRASIL, 2015).

De tal modo, o número de participantes frequentes da EJA, vem aumentando cada vez mais nesses exames, a partir de 2009.

Dentre as disciplinas avaliadas no ENEM, também se encontra a Educação Física. Conquanto o ENEM seja proporcionado a todos os estudantes, diante do fato de a Educação Física ser facultada aos alunos da EJA na legislação, os deixa em desvantagem, no que se refere a seus desempenhos, dificultando, assim, a inserção desses jovens e adultos no ensino superior. (BRASIL, 2018; PONTES JR et al., 2017).

Além do mais, existe o Exame Nacional para Certificação de Competências de Jovens e Adultos (ENCCEJA) que analisa competências, habilidades e saberes de jovens e adultos que não concluíram o ensino fundamental e médio na idade adequada, possibilitando a certificação e declaração de proficiência, para que o aluno conclua o ensino fundamental e médio (BRASIL, 2017).

O ENCCEJA tem como objetivo, construir uma referência nacional de avaliação, oferecer avaliação para fins de correção de fluxo escolar, construir, consolidar e divulgar os resultados na busca de melhorias no âmbito da EJA, construir parâmetros para autoavaliação e possibilitar o desenvolvimento de estudos e indicadores sobre educação brasileira. Para participar do ENCCEJA é necessário ter o mínimo de 15 anos para o ensino fundamental e 18 anos para o ensino médio (BRASIL, 2017).

Dentre as disciplinas contempladas, se encontra também a Educação Física, que se antepõe aos pré-requisitos, visto que, o exame exige um componente de prática facultativa.

É importante considerar que, ainda, $2 \%(n=1)$ relatou não gostar de Educação Física, considerando-a como "perda de tempo" para o estudo de outras disciplinas. Mas, qual motivo levou este aluno a ter essa percepção de Educação Física como um obstáculo?

Possivelmente, o relato desse estudante teve como subsídio suas experiências adquiridas culturalmente. Ao questioná-lo se o mesmo já tinha feito aula de Educação Física com o professor formado na área, a sua resposta foi que "não". Supõe-se que o mesmo não teve vivências necessárias com o conhecimento da Educação Física, e isso pode ter 


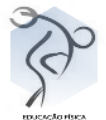

influenciado em sua concepção. Nesse sentido, evidencia-se que a Educação Física é um fator imprescindível e transformador dentro contexto escolar da EJA.

\section{CONSIDERAÇÕES FINAIS}

Após diversas reflexões sobre a concepção do componente curricular Educação Física em alunos do segmento da EJA, pode-se concluir que a maioria dos estudantes teve contato com a Educação Física em algum momento de suas vidas.

Muitos afirmaram compreender os benefícios que a Educação Física proporciona, quer sejam para a saúde e para o desenvolvimento educacional, físico e emocional.

Mais da metade dos alunos gostariam de tê-la como disciplina obrigatória, contudo, muitos ainda nunca participaram de uma aula de Educação Física na escola; alguns a enxergam como prática somente masculina, além de vê-la como obstáculo para estudo de outras disciplinas.

Diante do exposto, a medida a ser tomada, frente aos questionamentos apontados, se destaca a necessidade de gestores reavaliarem as escolas, suas dimensões e o público a quem está sendo direcionado, com um olhar mais aprofundado, visto que, as realidades vividas pelos alunos são de diversos níveis e a escola, juntamente com professores mediadores, podem criar ações para que esses discentes possam construir melhores perspectivas de vida e reconstituir seus sonhos de formação escolar.

Portanto, medidas de políticas públicas educacionais direcionada à EJA, como a inclusão da Educação Física, como componente obrigatório, poderá possibilitar o prazer e o empenho pelos estudos mesmo diante das dificuldades encontradas em seu contexto social. No entanto, destacamos as limitações do presente estudo e a necessidade de mais pesquisas voltadas para a Educação Física na EJA, em mais escolas, com números maiores de sujeitos investigados. É importante aumentar a visibilidade da EJA no cenário educacional, propor mudanças significativas para melhorar a qualidade de ensino e desenvolvimento desses alunos.

\section{REFERÊNCIAS}




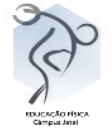

BRASIL. Instituto Nacional de Estudos e Pesquisas Educacionais Anísio Teixeira. 2017. Disponível em: http://portal.inep.gov.br/pt_BR/web/guest/educacao-basica/encceja. Acesso em: 29 de maio de 2019.

BRASIL. Instituto Nacional de Estudos e Pesquisas Educacionais Anísio Teixeira. 2018. Disponível em: http://portal.inep.gov.br/pt_BR/web/guest/enem. Acesso em: 29 de maio de 2019.

BRASIL. Lei de Diretrizes e Bases da Educação Nacional. Disponível em: http://www.planalto.gov.br/ccivil_03/Leis/19394.htm. Acesso em: 29 de maio de 2019.

BRASIL. Parâmetros Curriculares Nacionais: Educação Física. Ministério da Educação. Secretaria de Educação Fundamental. 3. ed. Brasília. 2001.

BRASIL. Referencial curricular de Rondônia. Secretaria de Estado da Educação de Rondônia. Educação de jovens e adultos - EJA: ensino fundamental e ensino médio. Rondônia, 2013.

CARVALHO, Rosa Malena. Educação física na educação de jovens e adultos. Revista Lugares de Educação, v. 3, n. 5, p. 37-49, 2013.

CARVALHO, Roseli Vaz. A juventude na educação de jovens e adultos: uma categoria provisória ou permanente? In: IX CONGRESSO NACIONAL DE EDUCAÇÃO. III ENCONTRO SUL BRASILEIRO DE PSICOPEDAGOGIA. PUCPR. 26 a 29 de outubro. 2009.

DARIDO, Suraya Cristina. Educação física na escola: conteúdos, suas dimensões e significados. In: UNIVERSIDADE ESTADUAL PAULISTA. Prograd. Caderno de formação: formação de professores didática geral. São Paulo: Cultura Acadêmica, v. 16. 2012.

DEVIDE, Fabiano Pries et al. Estudos de gênero na educação física brasileira. Motriz, v. 17, n. 1, p. 93-103, 2011.

DORNELLES, Priscila Gomes; FRAGA, Alex Branco. Aula mista versus aula separada? Uma questão de gênero recorrente na educação física escolar. Revista Brasileira de Docência, Ensino e Pesquisa em Educação Física, v. 1, n. 1, p. 141-156, 2009.

FREIRE, Elisabete dos Santos; OLIVEIRA, José Guilmar Mariz de. Educação Física no Ensino Fundamental: identificando o conhecimento de natureza conceitual, procedimentos e atitudinal. Motriz. Journal of Physical Education. UNESP, v. 10. p. 141-151, 2004.

GALVÃO, Zenaide. Educação física escolar: a prática do bom professor. Revista mackenzie de educação física e esporte, v. 1, n. 1, 2009. 


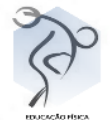

GOMES, André Taschetto; GARCIA, Isabel Krey. Perfil sócio-educacional de estudantes da Educação de Jovens e Adultos (EJA): um estudo de realidades e interesses acerca do conceito Energia. Latin-American Journal of Physics Education, v. 8, n. 3, p. 475-486. 2014.

GOMES, Romeu. Análise e interpretação de dados de pesquisa qualitativa. In: MINAYO, M. C. S. (Org.). Pesquisa Social: Teoria Método e Criatividade. Rio de janeiro - Petrópolis. Editora. Vozes. 2009. p. $79-80$.

GONÇALVES, Rosimeire. Desafios e contribuições da educação para alunos do eja. Itinerarius Reflectionis, v. 15, n. 2, p. 01-10, 2019.

GÜNTHER, Maria Cecília Camargo. O direito à educação física na educação de jovens e adultos. Revista. Bras. Ciênc. Esporte. v. 36, n. 2, p. 400-412. abr./jun. 2014.

HADDAD, Sérgio; SIQUEIRA, Filomena. Analfabetismo entre jovens e adultos no Brasil. Revista Brasileira de Alfabetização, v. 1, n. 2, 2016.

JAEL, Rafaela Reis Pereira. et al. As dificuldades no processo ensino - aprendizagem de Jovens e Adultos. II Jornada de Iniciação Científica da FACIG - 09 e 10 de novembro de 2017.

JESUS, Mauro Louzada de; DEVIDE, Fabiano Pries. Educação física escolar, co-educação e gênero: mapeando representações de discentes. Movimento, v. 12, n. 3, p. 123-140, 2006.

PONTES JR, Jose Airton Freitas et al. Estudantes da educação de jovens e adultos na Educação Física no Enem. Revista de estudios e investigación en psicología y educación, $\mathrm{n}$. 10, p. 76-80, 2017.

LOUZADA, Mauro; VOTRE, Sebastião; DEVIDE, Fabiano. Representações de docentes acerca da distribuição dos alunos por sexo nas aulas de Educação Física. Revista Brasileira de Ciências do Esporte, v. 28, n. 2, p. 55-68, 2007.

MINAYO, Maria Cecília de Souza; DESLANDES, Suely Ferreira; GOMES, Romeu Cruz. Pesquisa Social Teoria Método e Criatividade. Ed. Vozes. Petrópolis. 2008.

MIRANDA, Antonio Carlos Monteiro de; LARA, Larissa Michelle; RINALDI, Ieda Parra Barbosa. A Educação Física no ensino médio: saberes necessários sob a ótica docente. Motriz. Journal of Physical Education. UNESP, p. 621-630, 2009.

NAHAS, Markus Vinicius. Atividade física, saúde e qualidade de vida: conceito e sugestões para um estilo de vida ativo. 7. ed. Florianópolis. Ed. do autor. 2017

PEREIRA, Giane Moreira dos Santos; MAZZOTTI, Tarso Bonilha. Representações sociais de Educação Física por alunos trabalhadores do ensino noturno. Motriz. Journal of Physical Education. UNESP, p. 53-62, 2008. 


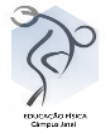

PEREIRA, Claudio Roberto de Jesus; SANTOS, Rafaela Gomes dos. O estágio supervisionado e as relações de gênero nas aulas de educação física: um relato de experiência. In: LINHARES, Wendell Luiz. (org). Ciências do esporte e educação física: uma nova agenda para a emancipação. Ponta Grossa, PR: Atena Editora, 2019. Cap. 1, p. 1 - 11.

PICH, Santiago; FONTOURA, Mariana Purcote. A cultura escolar da educação física no EJA: o paradoxo entre a ruptura com a noção de atividade e a falta da prática corporal. Educación Física y Ciencia, v. 15, n. 1, 2013.

SANTOS, Rafaela Gomes dos. Atividade Física, saúde e qualidade de vida na educação física escolar: uma análise de relações estabelecidas por diferentes autores. In: CARDOSO, B. L. C.; ALMEIDA, C. B.; FONSECA, E. O. S. Estilo de vida e saúde no contexto baiano. Goiânia: Kelps. 2018. Cap. 4, p. 65-85.

SOARES, Carmen Lúcia. Educação Física escolar: conhecimento e especificidade. Revista Paulista de Educação Física, p. 6-12, 1996.

SOARES, Carmem Lúcia, et al. Metodologia do ensino de educação física. São Paulo: Cortez. 1992. p. 33-38.

SOARES, Carmem Lúcia, et al. Metodologia do ensino de educação física. $2^{\circ}$ ed. São Paulo: Cortez, 2012. 